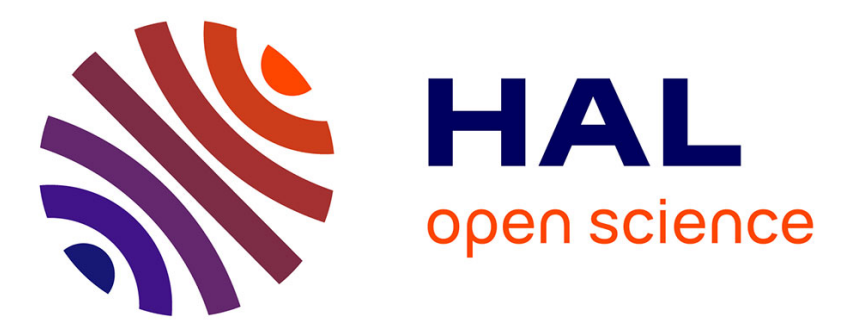

\title{
Treatment of chronic scapholunate instability: Results with three-ligament tenodesis vs. scapholunate and intercarpal ligamentoplasty
}

\author{
L. Athlani, N. Pauchard, F. Dap, G. Dautel
}

\section{- To cite this version:}

L. Athlani, N. Pauchard, F. Dap, G. Dautel. Treatment of chronic scapholunate instability: Results with three-ligament tenodesis vs. scapholunate and intercarpal ligamentoplasty. Hand Surgery and Rehabilitation, 2019, 38, pp.157 - 164. 10.1016/j.hansur.2019.03.002 . hal-03484952

\section{HAL Id: hal-03484952 \\ https://hal.science/hal-03484952}

Submitted on 20 Dec 2021

HAL is a multi-disciplinary open access archive for the deposit and dissemination of scientific research documents, whether they are published or not. The documents may come from teaching and research institutions in France or abroad, or from public or private research centers.
L'archive ouverte pluridisciplinaire HAL, est destinée au dépôt et à la diffusion de documents scientifiques de niveau recherche, publiés ou non, émanant des établissements d'enseignement et de recherche français ou étrangers, des laboratoires publics ou privés.

\section{다)(1) $(5$}

Distributed under a Creative Commons Attribution - NonCommerciall 4.0 International 
Treatment of chronic scapholunate instability: results with three-ligament tenodesis versus scapholunate and intercarpal ligamentoplasty

Traitement de la dissociation scapho-lunaire chronique : comparaison des résultats de la triple ténodèse versus la ligamentoplastie scapho-lunaire et intercarpienne

L. Athlani, N. Pauchard, F. Dap, G. Dautel

Service de chirurgie de la main, chirurgie plastique et reconstructrice de l'appareil locomoteur, Centre chirurgical Emile Gallé, CHU Nancy, France

\section{Corresponding author:}

Lionel ATHLANI

Service de chirurgie de la main, chirurgie plastique et reconstructrice de l'appareil locomoteur, Centre chirurgical Emile Gallé, CHU Nancy, France

+33667687957

lionel.athlani@gmail.com

\section{Other authors:}

Nicolas Pauchard, MD, pauchard.nicolas@neuf.fr

François Dap, MD, PhD, dapfrancois@gmail.com

Gilles Dautel, MD, PhD, gillesdautel@me.com

Key words: Wrist instability; Scapholunate dissociation; Scapholunate ligament; Threeligament tenodesis; Scapholunate and intercarpal ligamentoplasty

\section{Conflict of interest:}

Gilles Dautel and Nicolas Pauchard declare a conflict of interest with Arthrex®. 
The other authors declared no potential conflicts of interest with respect to the research, authorship, and/or publication of this article.

Acknowledgements: The authors wish to thank Dr. Joanne Archambault for English language editing assistance. The authors wish to thank Mr. Cyrille Martinet for the illustrations.

Funding statement: The authors received no financial support for the research, authorship, and/or publication of this article.

Informed consent: All patients gave their informed consent for this study 
1 Treatment of chronic scapholunate instability: results with three-ligament tenodesis

\section{vs. scapholunate and intercarpal ligamentoplasty}

Traitement de la dissociation scapho-lunaire chronique : comparaison des résultats de la triple ténodèse versus la ligamentoplastie scapho-lunaire et intercarpienne (1)

\section{Abstract}

In this retrospective case control/comparison study we compared the clinical and radiological outcomes in patients with chronic scapholunate dissociation treated with threeligament tenodesis $(3 L T)$ versus scapholunate and intercarpal ligamentoplasty (SLICL). Twenty patients with a mean age of 43 years were treated with the $3 \mathrm{LT}$ procedure and 26 patients with a mean age of 44 years with the SLICL procedure. All patients had chronic reducible scapholunate dissociation without chondral lesions. The two groups of patients were operated on by senior surgeons, at the same facility, over two different time periods. All patients were evaluated (pain, motion, strength, function, X-rays) with a mean follow-up of 28 months (12-49) in the 3LT group and 36 months (12-54) in the SLICL group. In the both groups, we found a significant improvement in pain levels, grip strength and functional scores (DASH and PRWE). The SLICL group had significantly less pain and greater grip strength than the $3 \mathrm{LT}$ group. Patients in the SLICL group had a greater improvement in their DASH and PRWE scores. The mean range of motion in flexionextension was $82^{\circ}\left(102^{\circ}\right.$ preoperative $)$ in the $3 \mathrm{LT}$ group and $113^{\circ}\left(115^{\circ}\right.$ preoperative $)$ in the SLICL group. In the 3LT, there was no significant improvement in the mean static and dynamic scapholunate gaps (3.6 and $4.8 \mathrm{~mm}$ postoperatively versus 3.9 and $4.9 \mathrm{~mm}$ preoperatively), or the scapholunate angle $\left(75^{\circ}\right.$ versus $\left.72^{\circ}\right)$. In the SLICL group, the mean static and dynamic gaps improved significantly (2.3 and $3.0 \mathrm{~mm}$ postoperatively versus 3.2 and $4.6 \mathrm{~mm}$ preoperatively), as did the scapholunate angle $\left(62^{\circ}\right.$ versus $\left.73^{\circ}\right)$. In the $3 \mathrm{LT}$ group, 4 patients developed osteoarthritis. 
better clinical and early radiological results than the 3LT technique.

\section{Résumé}

Dans cette étude rétrospective, nous avons comparé les résultats cliniques et radiologiques des patients présentant des dissociations scapho-lunaires chroniques traitées soit par une triple ténodèse selon Garcia-Elias (3LT) soit par une ligamentoplastie scapholunaire et intercarpienne (SLICL).

Vingt patients d'âge moyen de 43 ans ont été traités par une 3LT et 26 patients d'âge moyen de 44 ans avec une SLICL. Tous les patients présentaient une dissociation chronique réductible sans lésions cartilagineuses. Les deux groupes de patients avaient été opérés par des chirurgiens seniors, dans le même établissement, sur deux périodes différentes. Tous les patients ont été évalués (douleur, mobilités, force, scores fonctionnels, radiographies) avec un recul moyen de 28 mois (12-49) dans le groupe 3LT et de 36 mois (12-54) dans le groupe SLILC.

Dans les deux groupes, nous avons constaté une amélioration significative de l'évaluation de la douleur, de la force de préhension et des scores fonctionnels (DASH et PRWE). Le groupe SLICL avait significativement moins de douleur et une plus grande force de préhension que le groupe 3LT. Les patients du groupe SLICL avaient une meilleure amélioration de leurs scores DASH et PRWE par rapport au groupe 3LT. L'arc de mobilité en flexion-extension était de $82^{\circ}\left(102^{\circ}\right.$ en préopératoire) dans le groupe $3 L T$ et de $113^{\circ}$ (préopératoire $115^{\circ}$ ) dans le groupe SLICL. Dans le 3LT, il n'y a pas eu d'amélioration significative des espaces scapho-lunaires statiques et dynamiques (3,6 et 4,8 mm en postopératoire contre 3,9 et $4,9 \mathrm{~mm}$ en préopératoire) ou de l'angle scapho-lunaire $\left(75^{\circ}\right.$ versus $72^{\circ}$ ). Dans le groupe SLICL, les espaces scapho-lunaires statiques et dynamiques s'étaient significativement améliorés $(2,3$ et 3,0 mm en postopératoire contre 3,2 et 4,6 mm en préopératoire), de même que l'angle scapho-lunaire $\left(62^{\circ}\right.$ versus $\left.73^{\circ}\right)$. Dans le groupe 3LT, 4 patients avaient développé une arthrose.

En conclusion, la procédure SLICL pour la reconstruction du complexe scapho- 
57 lunaire a conduit à de meilleurs résultats cliniques et radiologiques à court terme que la 58 technique $3 \mathrm{LT}$.

59

60 Key words: Wrist instability; Scapholunate dissociation; Scapholunate ligament; Three-

61 ligament tenodesis; Scapholunate and intercarpal ligamentoplasty

62

63 Mots-clés : Dissociation scapho-lunaire ; Instabilité du carpe ; Ligament scapho-lunaire ;

64 Ténodèse à trois ligaments ; Ligamentoplastie scapho-lunaire

65 


\section{Introduction}

Scapholunate (SL) dissociation is the most common cause of intracarpal instability and is often diagnosed at a late stage [1]. Without treatment, scaphoid rotary subluxation and lunate dorsiflexion (dorsal intercalated segment instability, DISI) contribute to the development of SL advanced collapse (SLAC) osteoarthritis [2,3]. Several ligament reconstruction techniques have been described for treating symptomatic chronic reducible SL dissociation when no chondral lesions are present [4]. They all aim to reduce the scaphoid's flexion deformity, SL gap and DISI deformity to prevent SLAC osteoarthritis [5]. Moreover, recent biomechanical studies have highlighted the important stabilizing role of the extrinsic palmar and dorsal ligaments, which are considered secondary stabilizers for the SL complex $[6,7]$.

The three-ligament tenodesis (3LT) procedure described by Garcia-Elias et al. [8] uses a distally pedicled flexor carpi radialis (FCR) slip to reconstruct the dorsal segment of the SL interosseous ligament and the ligament complex on the distal pole of the scaphoid. In our practice, we initially used the $3 \mathrm{LT}$ procedure and then developed a new SL ligament reconstruction, the scapholunate intercarpal ligamentoplasty (SLICL) [9]. This procedure uses a free palmaris longus $(\mathrm{PL})$ graft to reconstruct the dorsal segment of the SL interosseous ligament and the dorsal intercarpal ligament. Here, we compare the preliminary results of these two procedures with a minimum follow-up of 12 months.

\section{Patients and methods}

2.1. Patients

This is an institutional review board-approved study reflecting the experience of senior surgeons at the same facility, over two different time periods. From May 2008 to June 2011, twenty patients with chronic SL dissociation were treated with the $3 \mathrm{LT}$ technique as described by Garcia-Elias et al. [8]. From March 2013 to September 2016, twenty-six patients with chronic SL dissociation were treated with the SLICL procedure as described by 
Athlani et al. [9] (Fig. 1). For the two procedures, stabilization was achieved by scapholunate and scaphocapitate pinning (1.2 mm K-wires) for 2 months.

Both groups were reviewed retrospectively at two different periods by the same independent examiner with the same methodology.

The two groups of patients had comparable characteristics and follow-up time. The mean age in the 3LT group was 43 years (22-56), and 15 of the patients were men. Eleven were right-handed, and 9 (45\%) had their dominant hand injured. Follow-up for the 3LT group was 28 months (12-49). The SLICL group had an average follow-up time of 36 months (12-54). The mean age in the SLICL group was 44 years (22-57 years), and 20 of the patients were men. Fourteen patients were right-handed, and 17 (65\%) was involved of their dominant hand. The time to surgery was similar between the two groups with a mean wait of 13 months (2-79) for the 3LT group and 14 months (3.5-72) for the SLICL group. Ten (50\%) patients performed heavy manual labor in the 3LT group and 15 patients (58\%) in the SLICL group.

\subsection{Review}

All patients underwent a full imaging assessment consisting of standard radiographs with posterior-anterior (PA) and lateral views, dynamic clenched fist views, PA view in radial deviation and ulnar deviation; CT arthrography was also done. All patients were diagnosed with chronic SL instability [2] — either dynamic or static reducible [11] with no chondral damage —which corresponds to stage 3 or 4 in the Garcia-Elias classification [8] (Figs. 2 and 3). Beforehand, an arthroscopy of the injured wrist was performed in all cases first to confirm the SL instability, quantify its magnitude [12], confirm that no repairable ligament remnant was present, and confirm the scaphoid was easily reducible and that no chondritis was present.

All patients were reviewed in person with a minimum follow-up of 12 months. After having collected each patient's consent, an independent examiner performed a clinical evaluation and requested radiographs. 

midline of the radiocarpal joint. The extensor retinaculum was opened between the third and

126 fourth compartments, and a dorsal capsulotomy performed according to Berger et al. [13].

127 They then harvested a $10 \mathrm{~cm}$ free PL graft through a short incision on the palmar side of the

128 wrist. The graft was then pretensioned with $3 \mathrm{~kg}$ for 2 min on a dedicated workstation

129 (Arthrex ${ }^{\circledR}$, Naples, Florida, United States). A first blind tunnel, $10 \mathrm{~mm}$ deep and $2.5 \mathrm{~mm}$ wide, was drilled at the site of the former scaphoid insertion of the dorsal segment of the SL interosseous ligament (proximal pole of the scaphoid). The posterior surface of the lunate was then drilled to create a shallow trench to serve as the interface for graft adhesion. A second blind tunnel of the same depth and width was drilled in the dorsal aspect of the

134 triquetrum near the radial side of the dorsal radiocarpal ligaments (DRCL), following the axis of the lunate trench. One of the two ends of the graft was then whip stitched over a length of 10 mm with a non-absorbable Fiberloop ${ }^{\mathrm{TM}}$ 4-0 (Arthrex ${ }^{\circledR}$, Naples, Florida, United States), wedged into the first proximal scaphoid tunnel, and secured in interference by means of an impacted 2.5 absorbable miniBioPushlock $^{\mathrm{TM}}$ (Arthrex $^{\circledR}$, Naples, Florida, United States). A 2.2 mm non-absorbable titanium MicroCorkscrew ${ }^{\mathrm{TM}}$ anchor (Arthrex ${ }^{\circledR}$, Naples, Florida, United States) was introduced into the lunate trench.

The dissociation was then reduced by manual maneuvers and pointed reduction

142 forceps [9]. Stabilization was achieved by scapholunate and scaphocapitate pinning (1.2 mm

143 K-wires). Fixing the graft in the second triquetral tunnel meant both tapering it and performing 144 a longitudinal plication. The central half was resected over a distance of $12 \mathrm{~mm}$ starting from 145 the entry point in the second tunnel. The two half strips thus obtained were folded back on 146 themselves to create a new intermediary graft end as thick as the other two ends over a 147 length of $6 \mathrm{~mm}$. This new end was then whip stitched over $10 \mathrm{~mm}$ before being inserted and 148 attached to the second blind tunnel by impacting a Pushlock. The graft located between the 
149 first two intraosseous fixation points was placed in the lunate trench, and then fixed by the 150 anchor sutures to create the first segment. A third blind tunnel of the same depth and width 151 was drilled at the level of the scaphoid isthmus near the scaphotrapeziotrapezoid (STT) joint 152 surface.

153 To create the second segment the remainder of the graft was again passed through 154 the lunate trench and fixed by the same anchor sutures, to allow for superposition of the two 155 segments in the tunnel. The remaining free end was resected beyond a distance of $8 \mathrm{~mm}$ 156 from the entry point in the third blind tunnel and then inserted into the tunnel. To do so, this 157 last end was whip stitched over $10 \mathrm{~mm}$ and fixed to the bottom of the third tunnel by 158 impacting a Pushlock. At this point we could test the tension of both segments with a tendon 159 hook. Capsular and retinacular stitching was performed.

160

\subsection{Postoperative protocol} Immediately following surgery, the wrist was immobilized in a volar plaster cast for 48 to 72 hours. Immobilization was extended for 2 months with a short-arm fiberglass splint. Kwires were removed 2 months postoperatively, at which point the patients began 1 month of self-directed rehabilitation. Radiographs were taken at 3 months postoperative, after which physiotherapy sessions were initiated. No heavy loads could be placed on the wrist for the

167 first 6 months postoperative.

\subsection{Clinical evaluation}

Pain was evaluated using a visual analog scale (VAS) (out of 10) at rest and during

171 effort. Grip strength in the operated and contralateral side in $\mathrm{kg} . \mathrm{F}$ was collected using a 172 Jamar ${ }^{\circledR}$ hydraulic hand dynamometer (Performance Health®, Charleville-Mézières, France).

173 The active joint range of motion (ROM) was measured in degrees during wrist flexion, 174 extension, radial deviation and ulnar deviation (accuracy of $1^{\circ}$ ). The functional outcomes 175 were evaluated using standardized questionnaires: DASH (/100) [14], PRWE (/100) [15]. 176 Postoperative complications were also recorded. 


\subsection{Radiographic evaluation}

At the follow-up visits, standard radiographic views, standard neutral PA and lateral views, and a clenched fist PA view were taken in all patients. The digital radiographs were viewed on OsiriX ${ }^{\odot}$ (Pixmeo ${ }^{\circledR}$ 2016, Geneva, Switzerland). The static and dynamic SL gaps $(\mathrm{SLG})$ in $\mathrm{mm}$ along with the $\mathrm{SL}$ angle $(\mathrm{SLA})$ in degrees were calculated $(0.1 \mathrm{~mm}$ accuracy for gaps and $1^{\circ}$ for angles). Values greater than $3 \mathrm{~mm}$ were considered pathological, as was an SLA greater than $70^{\circ}$ and a capitolunate angle (CLA) more than $15^{\circ}$ [16]. At the in-person review, the patients were assessed for any signs of necrosis of the proximal pole of the scaphoid and/or posterior horn of the lunate along with the development of scaphotrapeziotrapezoid (STT) or SLAC osteoarthritis.

\subsection{Statistical analysis}

The recorded data were summarised using mean values and ranges. The mean values obtained in the preoperative evaluation and at the last follow-up were compared using Student's $t$-test with any differences deemed significant with a type I error risk of $5 \%(P<$ 0.05).

\section{Results}

Results for both groups are given in Tables 1 and 2 . The 3LT group had 8 cases of dynamic instability and 12 of static. The SLICL group had 11 cases of dynamic instability and 15 of static. In every patient, the CT arthrography showed a tear of the SL interosseous ligament with contrast product leakage. During the arthroscopy evaluation, stage 2 instability was found in 4 cases and stage 3 in 16 cases in the 3LT group. In the SLICL group, stage 2 instability was found in 6 cases and stage 3 in 20 cases. There was no chondral damage. All the 3LT procedures were performed with an FCR and all the SLICL procedures using a free PL graft. The incision was healed within 2 weeks in all patients. The K-wires protecting the SL and scaphocapitate joints were removed at 2 months postoperative in all patients (range 
56 - 65 days), and then the rehabilitation protocol initiated. The time away from work averaged 6 months $(4-12)$ in the $3 L T$ group and 5 months $(0-12)$ in the SLICL group. In the 3LT group, 90 percent of patients had returned to the original job and in the SLICL group, 88 percent.

\subsection{Clinical evaluation}

At final follow-up, in the 3LT and SLICL groups, we found a significant $(p<0.05)$ reduction in pain levels at rest and during effort, a significant improvement in grip strength relative to the preoperative value and the contralateral side, and a significant improvement in the functional scores (DASH and PRWE). The SLICL group reported significantly less pain when compared with the 3LT group $(p<0.05)$. The SLICL group had significantly higher grip strength at final follow-up. The improvement was greater in the SLICL group than in the 3LT group (mean $14 \mathrm{Kg} . \mathrm{F}$ versus $8 \mathrm{Kg} . \mathrm{F} ; \mathrm{p}<0.05$ ). Also, the grip strength as a percentage of the contralateral side was higher in the SLICL group. Patients in the SLICL group had a larger improvement in their QuickDASH and PRWE scores, with a mean decrease of 40 points and 39 points, respectively, in this group versus a mean decrease of 18 points and 22 points, respectively, in the $3 \mathrm{LT}$ group $(\mathrm{p}<0.05)$. The mean $\mathrm{ROM}$ in flexion-extension was $82^{\circ}\left(102^{\circ}\right.$ preoperative) in the $3 \mathrm{LT}$ group and $113^{\circ}\left(115^{\circ}\right.$ preoperative $)$ in the SLICL group. Thus, the ROM in flexion-extension had significantly decreased $(p<0.05)$ in the $3 L T$ group $\left(20^{\circ}\right.$ reduction) but not significantly $(p>0.05)$ in the SLICL group $\left(2^{\circ}\right.$ reduction). Patients treated with the SLICL had better motion in flexion-extension than did the 3LT group. The differences in radial and ulnar deviation were not statistically significant between groups.

\subsection{Radiographic evaluation}

At final follow-up, in the 3LT group, there was no significant $(p<0.05)$ improvement of the mean static and dynamic SLG (3.6 and $4.8 \mathrm{~mm}$ postoperatively versus 3.9 and $4.9 \mathrm{~mm}$ preoperatively), or the SLA $\left(75^{\circ}\right.$ versus $\left.72^{\circ}\right)$ (Fig. 2). In the SLICL group, there was a significant $(p<0.05)$ improvement of the mean static and dynamic SLG $(2.3$ and $3.0 \mathrm{~mm}$ 
postoperatively versus 3.2 and $4.6 \mathrm{~mm}$ preoperatively), as well as the SLA ( $62^{\circ}$ versus $\left.73^{\circ}\right)$

234

235

236

237

238

239

240

241

242

243

244

245

246

247

248

249

250

251

252

253

254

255

256

257

258

259

260

(Fig. 3). The SLICL procedure led significantly greater improvement of the SLG and the SLA when compared with the $3 L T$ technique $(p<0.05)$.

\subsection{Complications}

There were no intraoperative complications or local postoperative infections in either group.

In the SLICL group, 3 patients (11.5\%) developed De Quervain's tenosynovitis that resolved with conservative treatment (brace and corticosteroid injection). There were no radiographic signs of bone lysis at the proximal pole of the scaphoid and/or the posterior horn of the lunate. However, we noted 2 cases $(7.5 \%)$ of asymptomatic loosening around miniBioPushlock ${ }^{\mathrm{TM}}$ implants (Fig. 4). The patients no required a new surgery but only radiological monitoring. At final follow-up, none of the patients had signs of SLAC osteoarthritis.

In the 3 LT group, 2 patients (10\%) developed type 1 complex regional pain syndrome (CRPS) that resolved with medical treatment. Seven patients $(35 \%)$ had palmar pain at entry point of the trans-scaphoid tunnel. Four patients (20\%) developed osteoarthritis (10\% STT osteoarthritis and 10\% SLAC). Two patients required a new surgical procedure: one case of early STT osteoarthritis requiring STT arthrodesis at 10 months, and one case of type 2 SLAC osteoarthritis reoperated at 32 months with a four-corner fusion (Fig. 5). Two other patients developed postoperative osteoarthritis (one STT osteoarthritis, one SLAC), but did not require further surgical intervention as of the last follow-up. There was one case (5\%) of scaphoid proximal pole radiolucency in the 3LT group.

\section{Discussion}

Based on this study's findings, the 3LT and the SLICL procedures can significantly reduce pain and increase grip strength. The clinical and radiological outcomes were better with the SLICL technique than the 3LT. The SLICL group reported significantly less pain at 
rest and during effort than the 3LT group. Grip strength in the SLICL group had recovered to

262

263

264

265

266

267

268

269

270

271

272

273

274

275

276

277

278

279

280

281

282

283

284

285

286

287

288

a mean of $89 \%$ when compared with the contralateral side. For the 3LT group, grip strength was $76 \%$. This difference was also statistically significant. When compared with preoperative values, there was significantly decreased flexion and extension in the $3 \mathrm{LT}$ group only. The preoperative values were similar in the two groups. The mean ROM had decreased by $20^{\circ}$ in the $3 L T$ group while the decrease was $2^{\circ}$ in the SLICL group. At final follow-up, the SLICL group had better motion in flexion and extension. Differences between the two procedures in radial and ulnar deviation were not significant.

The 3LT procedure [8] uses a distally pedicled slip of FCR to reconstruct the dorsal segment of the SL interosseous ligament and vertically reposition the scaphoid. This technique is considered the benchmark and has served as the basis for numerous clinical studies $[8,17,18]$. Authors of these study described a loss of ROM and grip strength after ligament reconstruction. At 46 months' follow-up, Garcia-Elias et al. [8] reported an average postoperative $\mathrm{ROM}$ in flexion-extension of $103^{\circ}$ and the grip strength was $65 \%$ of the contralateral side. At 10.5 months' follow-up, Kalb et al. [18] reported better recovery of grip strength with an average $80 \%$ of the noninvolved side. Average postoperative ROM in flexion-extension was $88^{\circ}$. In the $3 \mathrm{LT}$ group, the average postoperative ROM in flexion was $39^{\circ}$ in our study while Garcia-Elias et al. [8] reported $51^{\circ}$ and Kalb et al. [18] reported $35^{\circ}$. In the SLICL group, this amplitude was better with a mean $57^{\circ}$. This relative preservation of wrist flexion with the SLICL procedure can be attributed to not using a volar approach or the FCR.

In the SLICL group, we found a significant improvement in SLG and SLA, with a return to normal values [16]. This procedure has corrected the radiologic features of SL dissociation. In the 3LT group, the SLG and SLA did not decrease significantly. De Smet et al. [17] noted a significant reduction of the SLG (4.25 $\mathrm{mm}$ vs. $3.29 \mathrm{~mm}$ preoperative) and the SLA ( $77^{\circ}$ vs. $68^{\circ}$ preoperative) at 39 months' follow-up. However, the SLG and SLA were considered normal in only $33 \%$ and $25 \%$ of patients, respectively.

In the 3LT group, we found seven cases of persistent palmar pain. Talwalker et al. 
[19] noted four cases, three of which were treated surgically by excising a neuroma of the palmar branch of the median nerve.

We also found two cases (10\%) of postoperative STT osteoarthritis. Poor positioning at the entry point of the scaphoid tunnel may have caused joint penetration, or even a modification of articular congruence, owing to pressure exerted by the tenodesis. In the SLICL group, the rate of SLAC-type osteoarthritis was $0 \%$ while it was $10 \%$ (2 cases) in the $3 L T$ group. This rate was similar to that found in the literature: $5 \%$ for Chabas et al. [20], 12.5\% for Nienstedt et al. [21], 13\% for Moran et al. [22], 23\% for Garcia Elias et al. [8]. Finally, we also observed a case of scaphoid proximal pole radiolucency six months postoperatively. One case of avascular necrosis of the scaphoid was reported by De Smet and Van Hoonacker [23]. In the SLICL group, no bone-related complications were found. Since no anteroposterior scaphoid transosseous tunnel was made, there were no radiological signs of necrosis in the proximal pole of the scaphoid or signs of osteoarthritis in 302 the STT joint. Limitations of this comparative study include the relatively short follow-up period and small patient populations in each group. However, the mean sample size and mean follow-up are similar to that found in the literature. Comparisons may be affected by the different time periods, as the authors replaced one technique (3LT) with a new technique (SLICL). Longterm follow-up as well as the inclusion of other chronic SL instability cases will provide greater insight into the optimal management of this difficult problem.

\section{Conflict of interest:}

311 Gilles Dautel and Nicolas Pauchard declare a conflict of interest with Arthrex®. The other authors declared no potential conflicts of interest with respect to the research, authorship, and/or publication of this article. language editing assistance. The authors wish to thank Mr. Cyrille Martinet for the 
317 illustrations.

318

319 Funding statement: The authors received no financial support for the research, authorship, 320 and/or publication of this article.

321

322 Informed consent: All patients gave their informed consent for this study

323

324 


\section{References}

1. Gelberman RH, Cooney WP $3^{\text {rd }}$, Szabo RM. Carpal instability. Instr Course Lect 2001;50:123-34.

2. Larsen CF, Amadio PC, Gilula LA, Hodge JC. Analysis of carpal instability: I. Description of the scheme. J Hand Surg Am 1995;20:757-64.

3. Watson HK, Ballet FL. The SLAC wrist: scapholunate advanced collapse pattern of degenerative arthritis. J Hand Surg Am 1984;9:358-65.

4. Crawford K, Owusu-Sarpong N, Day C, lorio M. Scapholunate ligament reconstruction: A critical analysis review. J Bone Joint Surg Rev 2016;4:e41-8.

5. Linscheid RL, Dobyns JH. Treatment of scapholunate dissociation. Rotatory subluxation of the scaphoid. Hand Clin 1992;8:645-52.

6. Mitsuyasu H, Patterson RM, Shah MA, Buford WL, Iwamoto Y, Viegas SF. The role of the dorsal intercarpal ligament in dynamic and static scapholunate instability. J Hand Surg Am 2004;29:279-88.

7. Short WH, Werner FW, Green JK, Sutton LG, Brutus JP. Biomechanical evaluation of ligamentous stabilizers of the scaphoid and lunate: part III. J Hand Surg Am 2007;32:297-309.

8. Garcia-Elias M, Lluch AL, Stanley JK. Three-ligament tenodesis for the treatment of scapholunate dissociation: indications and surgical technique. J Hand Surg Am 2006;31:125-34.

9. Athlani L, Pauchard N, Dautel G. Radiological evaluation of scapholunate intercarpal ligamentoplasty for chronic scapholunate dissociation in cadavers. J Hand Surg Eur 2018;43:387-93.

10. Tang JB, Giddins G. Why and how to report surgeons' levels of expertise. J Hand Surg Eur 2016;41:365-6.

11. Watson HK, Weinzweig J, Zeppieri J. The natural progression of scaphoid instability. Hand Clin 1997;13:39-49.

12. Dreant N, Dautel G. Development of an arthroscopic severity score for scapholunate 
instability. Chir Main 2003;22:90-4.

13. Berger RA, Bishop AT, Bettinger PC. New dorsal capsulotomy for the surgical exposure of the wrist. Ann Plast Surg 1995;35:54-9.

14. Hudak PL, Amadio PC, Bombardier C. Development of an upper extremity outcome measure: the DASH (disabilities of the arm, shoulder and hand). The Upper Extremity Collaborative Group (UECG). Am J Ind Med 1996;29:602-8.

15. MacDermid JC, Turgeon T, Richards RS, Beadle M, Roth JH. Patient rating of wrist pain and disability: a reliable and valid measurement tool. J Orthop Trauma 1998;12:577-86.

16. Larsen CF, Mathiesen FK, Lindequist S. Measurement of carpal bone angles on lateral wrist radiographs. J Hand Surg Am 1991;16:888-93.

17. De Smet L, Goeminne S, Degreef I. Does the "three-ligament tenodesis" procedure restore carpal architecture in static chronic scapholunate dissociation? Acta Orthop Belg 2013;79:271-4.

18. Kalb K, Blank S, Van Schoonhoven J, Prommersberger KJ. Stabilization of the scaphoid according to Brunelli as modified by Garcia-Elias, Lluch, and Stanley for the treatment of chronic scapholunate dissociation. Oper Orthop Traumatol 2009;21:42941.

19. Talwalkar SC, Edwards AT, Hayton MJ, Stilwell JH, Trail IA, Stanley JK. Results of tri-ligament tenodesis: a modified Brunelli procedure in the management of scapholunate instability. J Hand Surg Br 2006;31:110-7. tenodesis for treatment of scapholunate instability: a retrospective study of 19 patients. J Hand Surg Am 2008;33:1469-77.

21. Nienstedt F. Treatment of static scapholunate instability with modified Brunelli tenodesis: results over 10 years. J Hand Surg Am 2013;38:887-92. tenodesis for treatment of scapholunate instability. J Hand Surg Am 2006;31:1438- 
46.

23. De Smet L, Van Hoonacker P. Treatment of chronic static scapholunate dissociation with the modified Brunelli technique: preliminary results. Acta Orthop Belg

384 2007;73:188-91.

385 


\section{Figure legends}

387 Fig. 1. Diagram illustrating the $3 \mathrm{LT}$ technique as described by Garcia-Elias et al. (A). The 388 SLICL technique as described by Athlani et al. (B). FCR: flexor carpi radialis; PL: palmaris 389 longus; DICL: dorsal intercarpal ligament; DRTL: dorsal radiotriquetral ligament; $M 2$ : second 390 metacarpal; M3: third metacarpal.

391

392 Fig. 2. Example of scapholunate dissociation detected on anteroposterior (A) and lateral (B) 393 radiographs. Postoperative anteroposterior (C) and lateral (D) radiographs at 46 months' 394 follow-up after the 3LT procedure.

395

Fig. 3. Example of scapholunate dissociation detected on anteroposterior (A) and lateral (B)

397 398 399 400 401 402

403 404 405 406 407 408 409 410

411 Table 2. Comparison of differences in the clinical and radiographic outcomes between three412 ligament tenodesis (3LT) and scapholunate intercarpal ligamentoplasty (SLICL) 


\section{Dorsal}
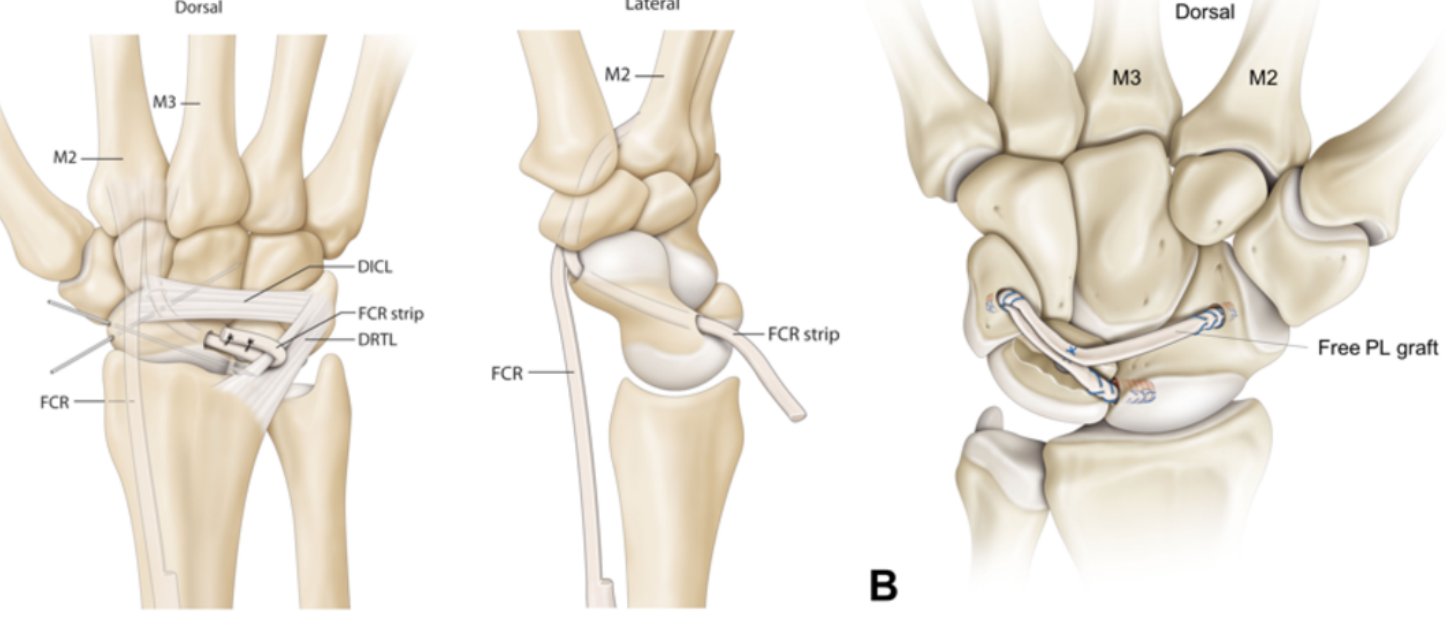


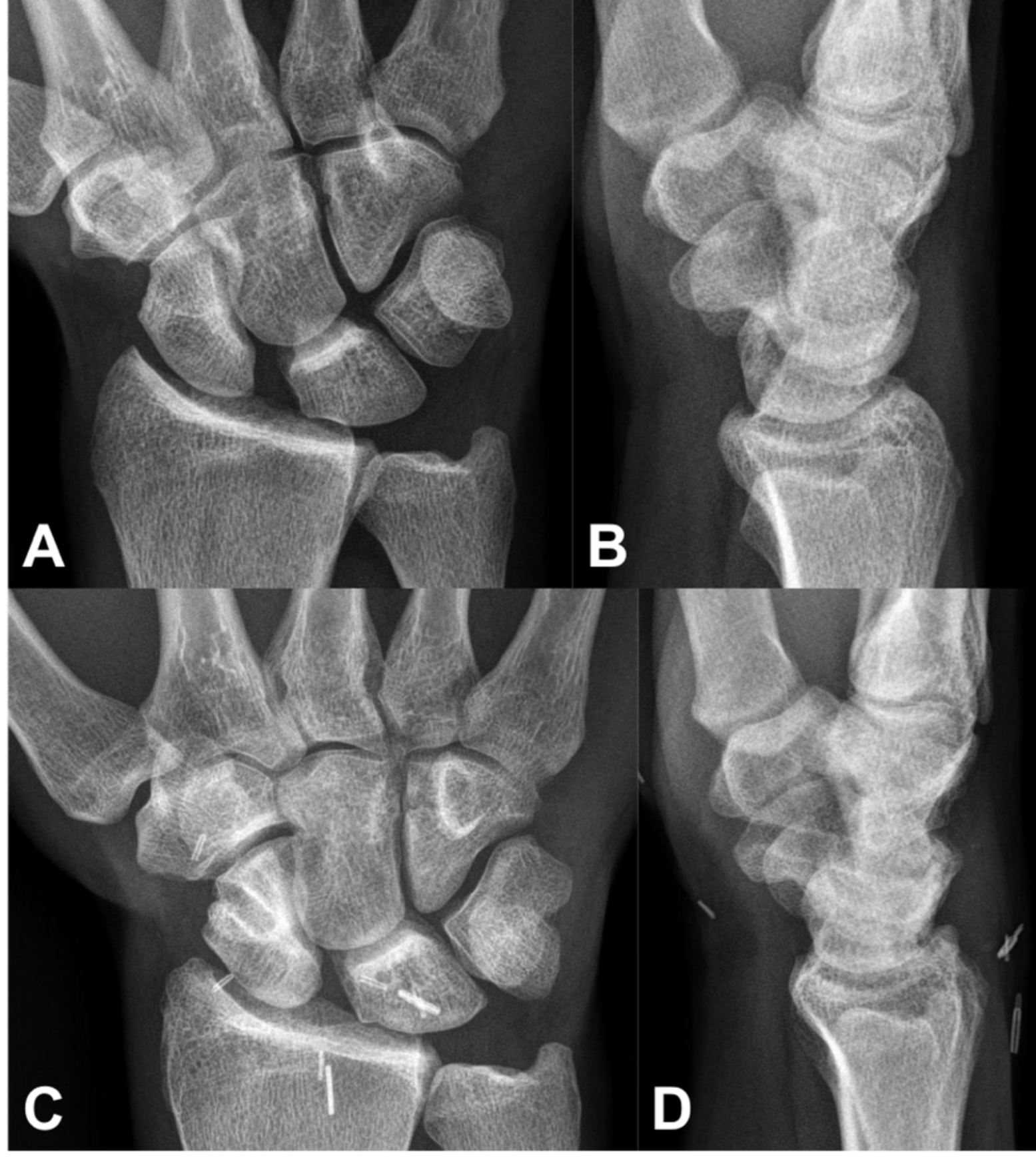




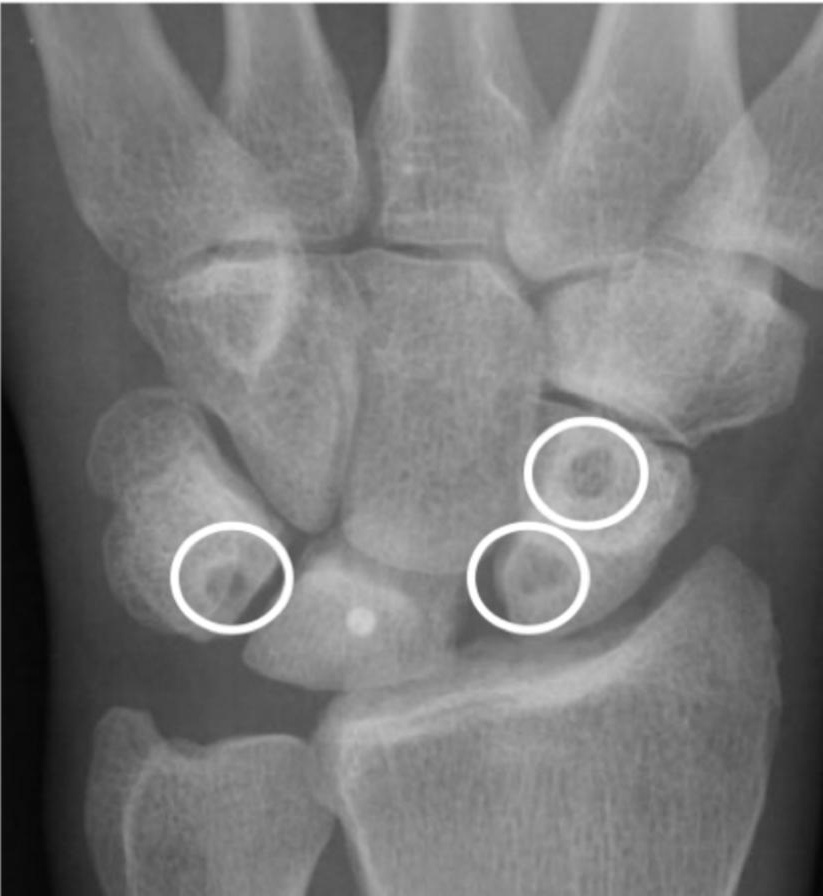


Table 1. Clinical and radiographic outcomes (mean) for patients treated with the three-ligament tenodesis (3LT) and scapholunate intercarpal ligamentoplasty (SLICL) procedures

\begin{tabular}{|c|c|c|c|c|c|c|}
\hline Average value & $3 L T(n=20)$ & & & SLICL $(n=26)$ & & \\
\hline & Preoperative & Last follow-up & $p$ & Preoperative & Last follow-up & $p$ \\
\hline Pain at rest (VAS) $(/ 10)$ & 3.2 & 1.6 & 0.01 & 4.5 & 0.4 & 0.01 \\
\hline Pain during effort $(/ 10)$ & 6.4 & 4.9 & 0.01 & 6.7 & 1.9 & 0.01 \\
\hline \multirow[t]{2}{*}{ Grip strength (Kg.F) } & 24 & 32 & 0.01 & 26 & 40 & 0.01 \\
\hline & $57 \% \mathrm{CL}$ & $76 \%$ CL & & $59 \% \mathrm{CL}$ & $89 \%$ CL & \\
\hline Flexion $\left(^{\circ}\right)$ & 52 & 39 & 0.01 & 59 & 57 & 0.663 \\
\hline Extension $\left(^{\circ}\right)$ & 50.5 & 43 & 0.01 & 56 & 56 & 0.885 \\
\hline Ulnar deviation $\left(^{\circ}\right)$ & 30 & 24 & 0.01 & 32 & 32 & 0.876 \\
\hline Radial deviation $\left({ }^{\circ}\right)$ & 17 & 14 & 0.05 & 16 & 16 & 0.731 \\
\hline DASH (/100) & 48.9 & 31.3 & 0.01 & 57.5 & 17.5 & 0.01 \\
\hline PRWE (/100) & 55.5 & 33.6 & 0.01 & 52.6 & 13.6 & 0.01 \\
\hline
\end{tabular}




\begin{tabular}{|c|c|c|c|c|c|c|}
\hline $\begin{array}{l}\text { Static scapholunate gap } \\
(\mathrm{mm})\end{array}$ & 3.9 & 3.6 & 0.477 & 3.2 & 2.3 & 0.01 \\
\hline $\begin{array}{l}\text { Dynamic scapholunate gap } \\
(\mathrm{mm})\end{array}$ & 4.9 & 4.8 & 0.793 & 4.6 & 3.0 & 0.01 \\
\hline Scapholunate angle $\left(^{\circ}\right)$ & 72 & 75 & 0.356 & 73 & 62 & 0.01 \\
\hline SLAC arthritis & 0 & 2 & - & 0 & 0 & - \\
\hline
\end{tabular}


Table 2. Comparison of differences in the clinical and radiographic outcomes between three-ligament tenodesis (3LT) and scapholunate intercarpal ligamentoplasty (SLICL)

\begin{tabular}{|c|c|c|c|}
\hline Average change & $3 L T(n=20)$ & SLICL $(n=26)$ & $p$ \\
\hline Pain at rest (VAS) (/10) & -1.6 & -4.1 & 0.01 \\
\hline Pain during effort $(/ 10)$ & -1.5 & -4.8 & 0.01 \\
\hline Grip strength (Kg.F) & +8 & +14 & 0.01 \\
\hline Flexion $\left(^{\circ}\right)$ & -13 & -2 & 0.01 \\
\hline Extension $\left({ }^{\circ}\right)$ & -7.5 & 0 & 0.01 \\
\hline Ulnar deviation $\left(^{\circ}\right)$ & -6 & 0 & 0.746 \\
\hline Radial deviation $\left(^{\circ}\right)$ & -3 & 0 & 0.896 \\
\hline DASH (/100) & -18 & -40 & 0.01 \\
\hline PRWE (/100) & -22 & -39 & 0.01 \\
\hline $\begin{array}{l}\text { Static scapholunate gap } \\
(\mathrm{mm})\end{array}$ & -0.3 & -0.9 & 0.01 \\
\hline
\end{tabular}


Dynamic scapholunate gap

$-0.1$

$-1.6$

0.01

(mm)

Scapholunate angle $\left(^{\circ}\right)$

$+3$

$-11$

0.01 